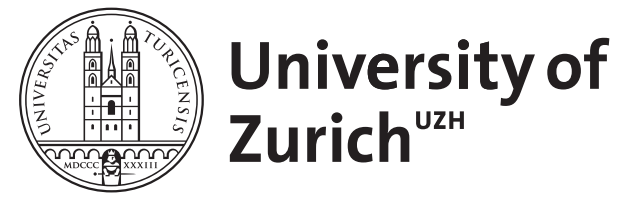

\title{
Vita Servii
}

Bayer, Karl ; Zogg, Fabian

DOI: https://doi.org/10.1515/9783110473940-013

Posted at the Zurich Open Repository and Archive, University of Zurich

ZORA URL: https://doi.org/10.5167/uzh-189191

Book Section

Published Version

Originally published at:

Bayer, Karl; Zogg, Fabian (2020). Vita Servii. In: Zogg, Fabian. Appendix Vergiliana : Lateinisch deutsch. Berlin/Boston: De Gruyter, 254-257.

DOI: https://doi.org/10.1515/9783110473940-013 


\section{VITA SERVII}

[I] In exponendis auctoribus haec consideranda sunt: poetae vita, titulus operis, qualitas carminis, scribentis intentio, numerus librorum, ordo librorum, explanatio.

[2] Vergilii haec vita est: [3] patre Vergilio matre Magia fuit; civis Mantuanus, quae civitas est Venetiae. [4] diversis in locis litteris operam dedit; nam et Cremonae et Mediolani et Neapoli studuit. [5] adeo autem verecundissimus fuit, ut ex moribus cognomen acceperit; nam dictus est 'Parthenias'. omni vita probatus uno tantum morbo laborabat; nam inpatiens libidinis fuit.

[6] Primum ab illo hoc distichon factum est in Ballistam latronem:

'monte sub hoc lapidum tegitur Ballista sepultus; nocte die tutum carpe, viator, iter.'

scripsit etiam septem sive octo libros hos: Cirin Aetnam Culicem Priapeia Catalepton Epigrammata Copam Diras. [7] postea ortis bellis civilibus inter Antonium et Augustum Augustus victor Cremonensium agros, quia pro Antonio senserant, dedit militibus suis. qui cum non sufficerent, his addidit agros Mantuanos, sublatos non propter civium culpam, sed propter vicinitatem Cremonensium: unde ipse in Bucolicis:

'Mantua vae miserae nimium vicina Cremonae.'

amissis ergo agris Romam venit et usus patrocinio Pollionis et Maecenatis solus agrum, quem amiserat, meruit. tunc ei proposuit 


\section{SERVIUS-VITA}

[I] Bei der Erklärung der Autoren ist Folgendes zu betrachten: das Leben des Dichters, der Titel des Werkes, die Beschaffenheit des Gedichtes, die Absicht des Schreibenden, die Zahl der Bücher, die Reihenfolge der Bücher, die Erklärung.

[2] Vergils Leben ist folgendes: [3] Er stammte vom Vater Vergil, von der Mutter Magia, 〈und war〉 Bürger Mantuas, einer Bürgergemeinde, die in Venetien liegt. [4] An verschiedenen Orten betrieb er die Wissenschaft; denn er hat in Cremona, in Mailand und in Neapel studiert. [5] Er war aber so überaus schüchtern, dass er auf Grund seines Wesens seinen Beinamen bekam; er wurde nämlich ,Parthenias` genannt. Im ganzen Leben bewährt, litt er nur an einer einzigen Krankheit; denn er konnte die Begierde nicht meistern.

[6] Zuerst wurde von ihm folgendes Distichon auf den Räuber Ballista verfasst:

»Hier unter diesem Steinberg liegt Ballista begraben; wandle bei Nacht und Tag, Wandrer, auf sicherem Weg!"

Er schrieb auch folgende sieben oder acht Bücher: Ciris, Aetna, Culex, Priapeen, Catalepton, Epigramme, Copa und Dirae. [7] Als später die Bürgerkriege zwischen Antonius und Augustus ausgebrochen waren, gab der siegreiche Augustus die Ländereien der Bewohner von Cremona, weil diese sich für Antonius eingesetzt hatten, seinen Soldaten. Als sie nicht ausreichten, fügte er ihnen die Ländereien Mantuas hinzu, die den Bürgern nicht wegen einer Schuld der Bürger, sondern wegen der Nachbarschaft Cremonas weggenommen wurden. Daher sagt er selbst in den Bucolica:

"Mantua, wehe, benachbart zu sehr dem armen Cremona!«

Nach Verlust seines Grundbesitzes also kam er nach Rom, und durch den Schutz des Pollio und Maecenas gewann er allein den Grundbesitz, den er verloren hatte, wieder. Dann schlug ihm 
Pollio, ut carmen bucolicum scriberet, quod eum constat triennio scripsisse et emendasse. [8] item proposuit Maecenas Georgica, quae scripsit emendavitque septem annis. [9] postea ab Augusto Aeneiden propositam scripsit annis undecim, sed nec emendavit nec edidit; unde eam moriens praecepit incendi.

[Io] Augustus vero, ne tantum opus periret, Tuccam et Varium hac lege iussit emendare, ut superflua demerent, nihil adderent tamen; [II] unde et semiplenos eius invenimus versiculos, ut 'hic cursus fuit', et aliquos detractos, ut in principio; nam ab armis non coepit, sed sic:

'ille ego, qui quondam gracili modulatus avena

carmen et egressus silvis vicina coegi,

ut quamvis avido parerent arva colono,

gratum opus agricolis, at nunc horrentia Martis -

arma virumque cano.'

[I2] et in secundo libro aliquos versus posuerat, quos constat esse detractos; quos inveniemus, cum pervenerimus ad locum, de quo detracti sunt.

[13] Periit autem Tarenti, in Apuliae civitate. nam dum Metapontum cupit videre, valetudinem ex solis ardore contraxit. sepultus est autem Neapoli; in cuius tumulo ab ipso compositum est tale distichon:

'Mantua me genuit, Calabri rapuere, tenet nunc Parthenope; cecini pascua rura duces.' 
Pollio vor, er möge bukolische Dichtung schreiben, die er bekanntlich in drei Jahren schrieb und vollendet herausgab. [8] Ebenso schlug Maecenas ihm die Georgica vor, die Vergil in sieben Jahren schrieb und vollendet herausgab. [9] Danach schrieb er die von Augustus vorgeschlagene Aeneis in elf Jahren, emendierte sie aber weder noch gab er sie heraus; daher ordnete er auf dem Sterbebett an, sie solle verbrannt werden.

[Io] Augustus aber befahl, damit ein so großes Werk nicht untergehe, dem Tucca und Varius, es unter der Bedingung zu verbessern, dass sie Überflüssiges beseitigten, jedoch nichts hinzufügten; [II] daher finden wir denn auch seine Halbverse, z. B. "Hierhin ging der Kurs", und 〈stellen fest〉, dass irgendwelche Verse getilgt worden sind, z. B. am Anfang; denn er begann nicht mit „Waffen«, sondern so:

»Ich, jener Dichter, der einst sein Lied auf zierlichem Halme spielte und dann, den Wäldern entschritten, Nachbargefilde zwang, auf den Bauern, und sei er noch so gierig, zu hören, Dichtung, dem Landmann lieb, jetzt aber des Mavors grause Waffen besinge ich und den Mann."

[I2] Auch ins zweite Buch hatte er gewisse Verse gesetzt, die bekanntlich herausgenommen worden sind; wir werden sie vorfinden, wenn wir zu der Stelle gekommen sind, von der sie fortgenommen sind.

[I3] Er starb aber in Tarent, einer Stadt Apuliens. Denn während er Metapont zu sehen verlangte, zog er sich infolge der Sonnenglut eine Krankheit zu. Begraben ist er aber in Neapel; auf seinem Grabhügel steht folgendes von ihm selbst verfasstes Distichon:

"Mantua gab mir das Leben, Kalabrien nahm es, Neapel birgt mich; Weiden besang, Felder und Führer mein Lied.« 
